NBER WORKING PAPER SERIES

HYPERTENSION AND HAPPINESS ACROSS NATIONS

David G. Blanchflower

Andrew J. Oswald

Working Paper 12934

http://www.nber.org/papers/w12934

\author{
NATIONAL BUREAU OF ECONOMIC RESEARCH \\ 1050 Massachusetts Avenue \\ Cambridge, MA 02138 \\ February 2007
}

For advice and valuable discussions, we thank two anonymous referees and James Banks, Issy Bray, Bruce Charlton, Carol Graham, John Helliwell, Danny Kahneman, Avner Offer, Chris Owen, Robert Putnam, Donald Singer, Doug Staiger, Andrew Steptoe, and Margaret Thorogood. The second author's work was funded by an ESRC professorial research fellowship. The views expressed herein are those of the author(s) and do not necessarily reflect the views of the National Bureau of Economic Research.

(C) 2007 by David G. Blanchflower and Andrew J. Oswald. All rights reserved. Short sections of text, not to exceed two paragraphs, may be quoted without explicit permission provided that full credit, including $(\odot$ notice, is given to the source. 
Hypertension and Happiness across Nations

David G. Blanchflower and Andrew J. Oswald

NBER Working Paper No. 12934

February 2007

JEL No. I10

\section{ABSTRACT}

A modern statistical literature argues that countries such as Denmark are particularly happy while nations like East Germany are not. Are such claims credible? The paper explores this by building on two ideas. The first is that psychological well-being and high blood-pressure are thought by clinicians to be inversely correlated. The second is that blood-pressure problems can be reported more objectively than mental well-being. Using data on 16 countries, the paper finds that happier nations report lower levels of hypertension. The paper's results are consistent with, and seem to offer a step towards the validation of, cross-national estimates of well-being.

David G. Blanchflower

Department of Economics

6106 Rockefeller Hall

Dartmouth College

Hanover, NH 03755-3514

and NBER

david.g.blanchflower@dartmouth.edu

Andrew J. Oswald

Department of Economics

Warwick University

Coventry CV4 7AL

England

a.j.oswald@warwick.ac.uk 


\title{
Hypertension and Happiness across Nations
}

\author{
David G Blanchflower \\ Andrew J Oswald
}

Because humans are extremely social animals, their sense of well-being is to a large extent determined by their social interactions. In hierarchical societies, individuals at every level have to submit ... and the recognition of this submissiveness generates emotions such as shame, anger and depression. These emotions lead to the activation of physiological alarm systems such as the hypothalamic pituitary adrenal axis and the sympathetic nervous system. The chronic activation of these systems ... results in ... hypertension, atherosclerosis, major depression and autoimmune diseases. Roy (2004)

\section{$\underline{1 . \text { Introduction }}$}

For effective social and economic policies to be designed, it is necessary for policymakers to be able to measure human well-being. Simple things -- real Gross Domestic Product, lifespan, height, incidence of cancer -- can usefully be counted. Quantifying psychological well-being in a broader sense, in an objective way, is a more complicated task.

This paper examines national levels of happiness ${ }^{1}$ and the validity of different measures of psychological well-being. To do this, it explores the use of crossnational survey data on hypertension (that is, on problems of high blood-pressure). The paper estimates both well-being and blood-pressure equations. Using Pearson and Spearman rank tests, it argues that the structure of the coefficients on country dummy variables is similar in both kinds of regression equations. Happy countries seem to have less hypertension. This has a number of implications. First, it suggests that there may be a case to take seriously the subjective 'happiness' measurements made across the world: they follow a pattern like the (inverse of) high-blood-pressure estimates. Second, in constructing new kinds of economic and social policies in the future, where well-being rather than real income is likely to be a prime concern, there

\footnotetext{
1 Recent contributions from psychologists, economists, and other investigators, include Theodossiou 1998, Frey and Stutzer 2002, Easterlin 2003, Van Praag and Ferrer-I-Carbonell 2004, Smith et al 2005, and Gilbert 2006. Historians' perspectives are provided by Crafts (1997) and Offer (2006).
} 
are grounds for economists to study people's blood pressure. Third, the paper's findings are relevant to our understanding of what Chockalingam, Campbell and Fodor (2006) and Lawes et al (2006) describe as a global epidemic of high bloodpressure. The World Health Report 2002 identified hypertension -- one definition is blood pressure above 140/90 $\mathrm{mmHg}$-- as a major determinant of disability-adjusted life years; WHO estimates that 1 billion people live with hypertension.

Although the details of the causal processes are not fully understood, there is some evidence that happiness and heart rate are negatively associated among men, and that wellbeing is correlated with cortisol levels and cardiovascular behaviour (Steptoe et al 2005). Yet internationally comparable measures of hypertension, where the demographic and educational characteristics of randomly sampled people are known, are in short supply, and social scientists have paid little attention to the idea that blood pressure could play a role as a relevant variable.

Measured psychological well-being levels seem to vary across the industrialized nations. Countries like Denmark, Ireland and the Netherlands tend to score highly in standardized surveys, while nations such as Italy, Germany and Portugal come out as markedly less happy. Perhaps naturally, such research has an interdisciplinary feel and has attracted attention from many kinds of scholars ${ }^{2}$. Using regression equations or simple tabulations, large samples, and pooled data, a number of the small social-democratic countries of Europe are consistently found to be among the happiest nations.

While these multi-country studies' findings seem intriguing, commentators like Ostroot and Snyder (1985), Argyle (2001) and Kahneman and Riis (2005) point

\footnotetext{
2 Recent examples include Diener et al (1993), Diener et al (1995a, b), Kenny (1999), Veenhoven (1999), Di Tella et al (2001, 2003), Schyns (2002), Steel and Ones (2002), Blanchflower and Oswald (2004), Fahey and Smyth (2004), Graham (2005), and Dolan and Kahneman (2006).
} 
out that it is hard to know what to make of the cross-national claims. First, language differences raise the worry that words like 'life satisfaction' cannot be translated sufficiently consistently to ensure that the variations in reported well-being are meaningful. Second, cultural differences -- in some countries it may be less acceptable to admit to unhappiness -- further complicate inference. Third, when visited, these European nations anecdotally appear similar in wealth, and in most ways of living. None of these objections is definitive; but all of them mean there are doubts over the substantive interpretation of estimated cross-national happiness variation.

Authors such as Easterlin (1974), Clark and Oswald (1994), Inglehart (1996), Ng (1997), Oswald (1997), Diener (2000), Kahneman et al (2004), and Vemuri and Constanza (2006) have made a case for taking well-being data seriously in the evaluation of human welfare. This form of research may even presage some move away from simple GDP targets of the sort that have been favoured in post-war economic policy. However, to make progress on the construction of a national wellbeing index, a better empirical justification for the use of subjective life-satisfaction and happiness statistics is needed. The paper tries to pursue this aim and relies on one central idea. It is that individuals know whether a doctor has informed them that they suffer from blood pressure problems. Arguably, such knowledge is relatively free of the cultural and language problems that presumably bedevil questionnaire evidence on happiness. We implement a test around this. The paper assumes that people provide survey answers to questions about high blood-pressure difficulties in a relatively objective way. One advantage of information on reported blood-pressure problems, relative to much other health self-reporting, is that respondents must rely on what physicians have said to them. Moreover, it is known in the medical literature 
that self-reports of hypertension are correlated with objectively measured readings of blood pressure and seem to have high validity (Giles et al 1995, Muhajarine et al 1997, Vargas et al 1997, Martin et al 2000, Liman-Cost et al 2004, Alonso et al 2005, Yoon and Zhang 2006). The paper's results are also potentially relevant to the socalled socioeconomic gradient in health and well-being (see, for example, Marmot 2004). It is known that those of high social and occupational status suffer less actual illness, die later, and report better subjective health than the poor and low-status. Gravelle and Sutton (2006) provides a clear discussion of self-reported health measures and how they are used. Steptoe (2000) reviews evidence on the socioeconomic gradient in hypertension.

\section{Measuring well-being}

Subjective well-being patterns across nations might be scrutinized in various ways. Happiness correlates could be studied, for instance, in the search for corroboration. Di Tella et al (2003) show, encouragingly for the quality of subjective data, that in a sample of Western nations there is evidence that the rises and falls in suicide rates move in the opposite direction to changes in happiness. The null hypothesis of no correlation, however, can be rejected only at the $10 \%$ level. Bray and Gunnell (2006) demonstrate that suicide is negatively correlated with happiness, and can reject the null of a zero correlation at the 5\% level; but in a smaller sample Lester (2002) does not find such clear-cut results. Other national correlates studied in the literature include trust and political institutions (Hudson 2006, Helliwell 2003). None of these articles, however, is an attempt to understand the quality of different measures of mental well-being.

As Ostir et al (2001) and Joynt et al (2003) demonstrate, rates of depression and heart disease are linked. A review of related evidence is available in Rutledge 
and Hogan (2002). Steptoe and Wardle (2005), for example, offer evidence that blood pressure is inversely related to reported happiness. Their data come from middle-aged men and women, with positive 'affect' (a psychological term for a form of happiness) assessed through repeated ratings over a working day. Greater happiness is associated with lower salivary cortisol both on working and nonworking days, reduced fibrinogen stress responses, and lower ambulatory heart rate in men. These patterns, Steptoe and Wardle argue, are be independent of age, socioeconomic status, smoking, body mass and psychological distress. In addition, happiness is found to be inversely related to ambulatory systolic blood pressure on follow-up, again independently of potential confounders including negative affect. The results establish that affective states are linked to outcomes. Similarly, Lazaro et al (1993) shows that borderline hypertension is associated with worse GHQ mental strain scores.

The work of Jonas and Lando (2000) uncovers a positive connection between anxiety today and hypertension in the future. A population-based cohort of 3310 initially normotensive and chronic disease-free persons in the NHANES I Epidemiologic Follow-up Study is tracked through four follow-up waves (maximum, 22 years). The association between hypertension and baseline negative affect is analyzed using Cox proportional hazards regression, adjusting for baseline age, sex, race, education, smoking, alcohol use, diastolic and systolic blood pressure, body mass index, and change in body mass index as a time-dependent covariate. Steptoe et al (2005) paints a complementary picture. It demonstrates that levels of positive affect in middle-aged men and women are associated with reduced neuroendocrine, inflammatory, and cardiovascular activity. Well-being in the study is assessed by aggregating momentary experience samples of happiness over a working day and is 
found to be inversely related to cortisol output over the day. Once again, happiness is inversely related to heart rate measured using ambulatory monitoring methods. Strasser (1998) documents evidence that East Europeans have much higher blood pressure readings than citizens from Western Europe. This is interesting, from the perspective of the well-being literature, because it has long been known that Eastern Europe has particularly low happiness scores (Blanchflower, 2001). Banks et al (2006) argues that Americans are less healthy than Europeans; differences in blood pressure form part of the authors' evidence. Wolf-Maier et al (2003) and Stamler et al (1992) document blood pressure internationally and establish that education is inversely related to hypertension. Owen et al (2005) shows strong childhood influences. Colhoun et al (1998) provides a valuable summary of similar evidence.

Nevertheless, despite this epidemiological evidence on groups of medical subjects, relatively little is known, especially by economists, about national correlations between well-being and hypertension. The individual-level association between well-being and blood pressure is also imperfectly understood. Johannesson, Jonsson and Borgquist (1991) estimate a figure that individuals are willing to pay for hypertensive therapy, although conclude that the Contingent Valuation method does not work well.

\section{$\underline{\text { 3. Analysis }}$}

In this study the data set is Eurobarometer \#56.1. It collected identical survey information in September and October 2001 from approximately 15,000 randomly sampled individuals in Denmark, West Germany, Greece, Italy, Spain, France, Ireland, Luxembourg, the Netherlands, Portugal, the United Kingdom, East Germany, Finland, Sweden, Austria, and Belgium. Among other questions, one was: Would you say that you have had problems of high blood pressure? Answers could be given in 
four different boxes: not at all; no more than usual; rather more than usual; much more than usual. The presumption in the paper is that individuals who said yes had obtained such information from doctors.

We start with descriptive statistics. Using this 2001 European cross-section, Table 1(a,b) gives raw numbers on life-satisfaction and blood-pressure answers, where the well-being question in this case is the simple one: Would you say you are very satisfied, fairly satisfied, not very satisfied, or not at all satisfied with the life you lead? Table 1(c) gives a cross-tabulation for the two variables, which takes the expected pattern.

Table 2 sets out regression equations in which the dependent variable is a measure of reported high blood-pressure problems. These use Ordinary Least Squares and Ordered Logit methods. They are to be read vertically, and can be thought of as hypertension regression equations. Here the sample size in column 1 is 15,517 individuals. The OLS equations assign the numbers 1 to 4 to people's answers (where 4 is the most severe blood-pressure problems). The independent variables in the first column of Table 2 are country dummies, age, age squared, and a dummy variable for the gender of the respondent. 'Male' does not have an effect that is statistically significantly different from zero. Age in Column 1 of Table 2 enters with a well-determined linear positive effect; there is no evidence for a nonlinear term. The estimated dummy-variable coefficients for nations range from a high of 0.2695 for Portugal and 0.2197 for East Germany to lows of -0.1825 for Sweden and -0.1313 for the Netherlands. Belgium is the omitted, base country. According to these data, the measured levels of hypertension -- without controlling for personal characteristics other than age and gender -- are therefore high among, from the greatest levels downwards, the Portuguese, the East Germans, the West Germans, the 
Italians, and the Finns. Nations with low levels of hypertension are, from the lowest upwards, Sweden, the Netherlands, Denmark, the UK, and Ireland. Hypertensive nations might be expected to have shorter longevity. The latest Human Development Report shows, consistently, that Sweden currently has the longest lifespan of the 16 nations at 77.9 years for males, while Portugal at 73.9 years has the shortest length of life. There is, however, not an exact match. ${ }^{3}$

Column 2 of Table 2 adds an Age Left Schooling variable as a simple measure of the individual's level of education. It enters strongly negatively with a coefficient of -0.0035 and a t-statistic that allows the null of zero to be rejected at conventional confidence levels. This, although in a slightly unusual setting, is the familiar idea of a socio-economic gradient in health: more highly-educated people report fewer problems with hypertension. This is despite the fact that they presumably have more information from, and access to, physicians. Hierarchy's effects are one possible explanation (Roy 2004, Marmot 2004).

It is useful to ensure that the results are not being driven by the sub-sample of people who report the two highest levels of hypertension problems. To check this, we re-estimated column 2 of Table 2 as a simple probit equation, with a blood-pressure problems dependent variable being a 0-1 dummy for None and Any. The country dummy structure was approximately unaffected; it was correlated 0.97 with that from column 2 of Table 2 itself.

In its third column, Table 2 adds a further set of independent variables. These are controls for the individual's life experiences before the age of 18 (such as whether they grew up in a single-parent home), the individual's labour force status such as which if any kind of job and occupation they have, and a set of dummy variables

\footnotetext{
3 We thank Danny Kahneman for suggesting that we examine longevity.
} 
capturing different kinds of marital status. Adding these makes little difference to the country-dummy coefficients. Column 4 of Table 2 moves to an ordered logit estimator. Because the independent variable on blood pressure problems is not cardinal, the OLogit column is in principle to be preferred. Again the structure of the country dummies is not radically altered by going from Column 3 to Column 4 of Table 2. Age squared, however, now enters with a coefficient of -0.0003 and a tstatistic of 4.89 , so aging appears with a concave structure. Nevertheless, as the turning point in the quadratic is at greater than 100 years old, the substantive consequence for the age effect in going from Column 3 to 4 is small. To explore the robustness of the structure of this hypertension regression specification, Tables 3 and 4 set out the equations separately for the male and female sub-samples of, in the first columns, 7,400 and 8,117 people respectively. Encouragingly, the general equation structure looks similar for men and women. This is important for the paper's aim, namely, to isolate a unique and well-determined country pattern of well-being.

The ordering of the country-dummy values is close to identical in each table. One important difference is visible, however. For Europe's males, in Table 3, the variable Age Left Schooling enters with a negligible effect on blood pressure. In Table 4, for European females, there is a well-determined negative correlation, with, in Column 4, a coefficient of -0.0352 and t-statistic of 4.82 . It is only for females here that there is a clear socioeconomic gradient in reported blood pressure problems. No income measures are available in the data set so cannot be included.

It might be argued that the data should be partitioned ${ }^{4}$ into groups of individuals with different education levels. To check this, the specification of column 3 of Table 2 was re-estimated. This was done, first, on the subsample of those in the

\footnotetext{
${ }^{4}$ A referee suggested this approach.
} 
data set (57\%) who left schooling before the age of 18 and, second, on the subsample of those (the remaining $43 \%$ ) who left later than 18 . Country dummies were then extracted from these two regression equations. The sets of dummies exhibited a correlation coefficient of 0.9 , which suggests that partitioning does not affect the principal conclusion.

A range of well-being equations is presented in Table 5. The first three columns are for life-satisfaction as a dependent variable; the fourth column uses a happiness variable. Here the data sets differ. Column 1 is for the previous 2001 data set, \#56.1. Column 2 draws instead upon 185,711 randomly sample people from the Eurobarometer Trends files; it pools the years 1994, 1995 and 1997-to-2002 inclusive. Finally, Columns 3 and 4 of Table 5 use data on approximately 47,000 individuals from the pooled European Social Surveys of 2002 and 2004. Although not the focus of the paper, these well-being specifications generate the equation form now familiar from modern research on industrialized countries. There is a U-shape in age; males are less happy with their lives; education enters with a positive coefficient.

Two points follow from Table 5. First, regardless of the data set used, the estimated structure of the country dummy variables is similar. Denmark, for example, across the well-being regression equations is always the happiest country. Greece, Italy, Portugal and East Germany are always low in the well-being countryby-country rankings. Second, and of central importance to the paper's thesis, this structure is approximately the inverse of that found in the nations' dummy-variable coefficients in the earlier blood-pressure problems equations.

Figure 1 illustrates the pattern. It plots a measure of hypertension problems for each nation against a measure of the level of happiness by nation. The graph displays the country dummies from the fourth column of Table 2 against the country 
dummies from the fourth column of Table 5. Looking, using the final columns of Tables 2 and 5, at the top and bottom of the ordering: the lowest blood-pressure countries are Sweden (\#1), Denmark (\#2) and the UK (\#3) and these are ranked \#3, \#1 and \#8 in happiness; the three highest blood-pressure countries are West Germany (\#14), East Germany (\#15) and Portugal (\#16), and these are between \#12 and \#14 in the happiness league table. The only anomaly appears to be Finland; for reasons that are unclear, its position moves around across the different well-being rankings.

Figure 2 depicts the result in an alternative way. Here the sixteen nations are grouped -- by blood pressure -- into quartiles. The graph uses the coefficients from the third column of Table 2, plotted against, on the y-axis, the matching data for the nations' percentages of those saying they are very satisfied with their lives (so there is here no regression-equation correction). In the four countries with low levels of blood-pressure problems, $48.5 \%$ of individuals say they are very satisfied with life. Among the highest blood-pressure countries, namely, those in the top quartile of hypertension, only $22.5 \%$ of citizens give this satisfaction rating.

We also report Pearson correlation coefficients for blood-pressure dummies correlated with the country dummies from equations with various dependent variables for mental well-being. Arguably a more appropriate test relies only on the ordinality of the league-table positions in international measures of blood-pressure difficulties and psychological well-being. A Spearman's rank correlation test is therefore computed. These provide tests of the null hypothesis of no correlation between the country dummies in Table 5 and the country dummies in the right hand column of Table 2. 
The four columns in the matrix below are for correlations with the country dummies in the four columns of Table 5. The first three columns are life satisfaction equations; the fourth is a happiness equation.

Coefficients of Correlation Between the Country Dummies in Well-being and BloodPressure Equations:

$\begin{array}{lcccc}\text { Data set } & \begin{array}{c}\text { LifeSat } \\ \text { EB561 }\end{array} & \begin{array}{c}\text { LifeSat } \\ \text { Trends }\end{array} & \begin{array}{r}\text { LifeSat } \\ \text { ESS }\end{array} & \begin{array}{r}\text { Happiness } \\ \text { ESS }\end{array} \\ \text { Pearson's } & -0.648 & -0.495 & -0.600 & -0.597 \\ \text { Spearman's } & -0.638 & -0.479 & -0.526 & -0.553\end{array}$

Each of the rank correlation coefficients is significantly different from zero on a one tailed test with cut-off $\alpha=0.05(\mathrm{n}=16)$; the critical value of Spearman's rank correlation coefficient is 0.425 . For a two-tailed test, with $\alpha=0.025$, it is 0.507 . [McClave, J.T., P.G. Benson and T. Sincich (2001), Table XV11, Appendix B, page 1005.]

Whichever well-being measure is adopated in Table 5, there is evidence of an inverse relationship between national subjective well-being and national bloodpressure problems. For the data represented in Figure 1, Pearson's R is -0.597 and Spearman's rank correlation coefficient is -0.553 . Both are significantly different from zero, given the 16 observations on European nations, at the 5\% level. The pattern is the same if OLS coefficients are used.

Objective hypertension measures would be valuable. Kearney et al (2005) is one of the few modern papers to try to document the levels of statistically representative age-adjusted blood-pressure figures by nation. Its conclusions are approximately consistent with our numbers. For example, for Kearney's sample of six nations, among randomly sampled European males the highest levels of hypertension are found -- in the same order as in our sample -- within Germany 
followed by Italy and then Spain. It rates Sweden, England and Greece at lower levels. However, the range of European nations in the Kearney sample is too small to allow a full comparison, and the different national samples are collected in slightly different ways and years.

Could the paper's main result be some form of spurious correlation? One concern is the possibility that different degrees of information and health resources are provided to people across nations ${ }^{5}$. In a country where there are relatively few physicians, that nation's citizens may have greater levels of undiagnosed hypertension, which could lead to errors in the data provided earlier in the paper. This difficulty is an important one. We attempt to address it in the following way.

Assume that individuals are necessarily informed by their doctors that they have hypertension. A natural check is then to examine how the international patterns in reported levels of high blood-pressure correlate with the number of doctors per head of the population. If we take, for example, the data from the third column of Table 3's equation for males, and average across the 3 highest blood-pressure nations (East Germany, Portugal, Finland), the mean number of physicians per 100,000 people according to the latest Human Development Report data is 332. Across the 3 lowest blood-pressure nations here (Sweden, Netherlands, Denmark), it is almost identical, at 333 physicians per 100,000. This counter-argument to the difficulty of potentially different levels of medical advice across nations cannot be definitive. Yet it suggests that the differences we observe in hypertension levels are not in any simple sense because of cross-European differences in access to medical information.

A further check was done. We explored the patterns in a different measure of mental well-being, favoured by, for example, Goldberg et al (1997). It is a so-called

\footnotetext{
5 We thank Andrew Steptoe for discussions on this issue.
} 
GHQ (General Health Questionnaire) psychiatric measure. In this case, in Table 6, the dependent variable is a measure of psychological distress that comes from amalgamating answers to the questions:

Have you recently:

1. Lost much sleep over worry?

2. Felt constantly under strain?

3. Felt you could not overcome your difficulties?

4. Been feeling unhappy and depressed?

5. Been losing confidence in yourself?

6. Been thinking of yourself as a worthless person?

To the answers to each of these six, we assigned the integers $0,1,2,3$-- depending whether each was answered not at all, no more than usual, rather more than usual, much more than usual. The numerical answers were then summed. Overall, a mental distress score, denoted GHQ-N6, must by definition lie between 0 and 18. Across Europe, the mean of this psychological score is 3.6 (standard deviation 3.7). A more complete GHQ measure is often computed from 12 questions (Goldberg et al 1997). However, no other GHQ questions were available in the data set, but there is a precedent -- as in Huppert and Whittington 2003 and Hu et al 2006 -- for use of these 'negative' six questions (hence the abbreviation N6). The cross-country pattern in mental distress GHQ-N6 here is consistent with those found in happiness, lifesatisfaction and hypertension. This can be seen informally by inspection in Table 6; but, more formally, for the specification in column 3 of Table 6 , the country dummies in GHQ-N6 when correlated with those in the blood-pressure equation in column 3 of Table 2 produce a Pearson's correlation coefficient of 0.55 , which is significant at the $5 \%$ level. 
The focus of this paper has been upon country-level differences in well-being. Nevertheless, it is possible to get some feel for the individual-level correlation between hypertension and happiness. Table 7 estimates a life satisfaction equation which includes a blood-pressure independent variable that takes the form of a single dummy for any reported problems of hypertension or not. Although a cross-section regression equation of this type cannot uncover the direction of causality ${ }^{6}$, the hypertension measure enters significantly negatively in the life-satisfaction specification, with a t-statistic of approximately 20 across the various columns. Table 8 performs one further check. It replicates the same individual-level result in a lifesatisfaction equation estimated with data from the 1999/2000 sweep of the British National Child Development Study. This data set is a birth cohort of individuals born between the $3^{\text {rd }}$ and the $9^{\text {th }}$ March 1958, who were all aged 42 at the time of interview. Table 8 reveals that the indicator variable for high blood-pressure is again negative in all specifications. It is possible in this data set to allow for obesity, which is a known correlate with hypertension. The negative correlation remains once extra controls are included for body mass index (BMI) and its square, as well as also selfreported assessments of weight.

\section{$\underline{4 . \text { Conclusions }}$}

This paper is an attempt to study the levels of hypertension and happiness across nations. It draws upon data on 15,000 randomly sampled individuals from 16 countries (and on larger samples to provide measures of well-being). The paper provides evidence to suggest that happier nations report fewer blood-pressure problems. Figure 2 illustrates the principal conclusion.

\footnotetext{
6 In an equation with blood-pressure variable as the dependent variable, a negative association with well-being is again found.
} 
A modern literature has claimed that countries like Denmark, Ireland and the Netherlands are particularly happy while nations such as Germany, Italy and Portugal are less happy. Yet it is arguably implausible that words such as 'happiness' or 'satisfaction' can be communicated unambiguously and in exactly the same way across countries, so it is not easy to know whether such cross-national well-being patterns are believable.

The paper's main finding is that the pattern of the country dummies in tables like Table 2 is similar to the (inverse of the) pattern of the dummy variables for countries in a table like Table 5. This seems to be true whichever the chosen wellbeing proxy or data set. These results do not seem to be caused by different numbers of physicians across countries. Nevertheless, the persuasiveness of the paper rests on three assumptions:

(i) it is reasonable to treat survey evidence on high-blood-pressure problems as a proxy for objective hypertension (for example, Vargas et al 1997);

(ii) people report high blood-pressure in a more objective way than they report levels of happiness;

(iii) the patterns in Figures 1 and 2 are not merely the product of something special to this sample of nations.

It might be conjectured that the paper's conclusion is potentially illusory and a product of the fact that an inherently cheery nation will be optimistic about everything. However, it is not easy to believe that someone told by their doctor that they have a condition of high blood-pressure will have an incentive to conceal or misreport that. For researchers, the attraction of a blood-pressure question in surveys is that, because it relies on medical opinion given to the individual, it seems valuably different in character from conventional subjective well-being questions. 
Could the explanation for the pattern uncovered here be along the following lines: there is an omitted variable in both sets of equations for the intangible thing 'physical flourishing and good mental-well-being'? It may well be that this is an appropriate way to think. However, that appears not so much a criticism of the paper as much an interpretation of it. Psychological health cannot be measured easily but it is high in Denmark and low in East Germany, and this, at some still poorlyunderstood level, is what connects the observed data on happiness and hypertension. More research remains needed on how such connections may operate. 


\section{References}

Alonso A, Beunza JJ, Delgado-Rodriguez M, Martinez-Gonzalez MA. Validation of self-reported diagnosis of hypertension in a cohort of university graduates in Spain. BMC Public Health 2005; 5; Article 94.

Argyle M. The psychology of happiness. Routledge: London, Second edition; 2001.

Banks J, Marmot M, Oldfield Z, Smith JP. Disease and disadvantage in the United States and in England. Journal of the American Medical Association 2006; 295; 2037-2045.

Blanchflower DG. Unemployment, wellbeing and wage curves in Eastern and Central Europe. Journal of Japanese and International Economies 2001; 15; 364-402.

Blanchflower DG, Oswald AJ. Well-being over time in Britain and the USA. Journal of Public Economics 2004; 88; 1359-1386.

Bray I, Gunnell D. Suicide rates, life satisfaction and happiness as markers for population mental health. Social Psychiatry and Psychiatric Epidemiology 2006; 41; 333-337.

Chockalingam A, Campbell NR, Fodor JG. Worldwide epidemic of hypertension. Canadian Journal of Hypertension 2006; 22; 553-555.

Clark AE, Oswald AJ. Unhappiness and unemployment. Economic Journal 1994; $104 ; 648-659$.

Colhoun HM, Hemingway H, Poulter NR. Socioeconomic status and blood pressure: An overview analysis. Journal of Human Hypertension 1998; 12; 91-110.

Crafts NFR. Some dimensions of the 'quality of life' during the British industrial revolution. Economic History Review 1997; 50; 617-630.

Diener E. Subjective well-being - The science of happiness a proposal for a national index. American Psychologist 2000; 55; 34-43.

Diener E, Sandvik E, Seidlitz L, Diener M. The relationship between income and subjective well-being - relative or absolute. Social Indicators Research 1993; $28 ; 195-223$.

Diener E, Suh EM, Smith H, Shao L. National differences in reported subjective wellbeing - Why do they occur? Social Indicators Research 1995a; 34; 7-32.

Diener E, Diener M, Diener C. Factors predicting the subjective well-being of nations. Journal of Personality and Social Psychology 1995b; 69; 851-864.

Di Tella R, MacCulloch RJ, Oswald AJ. Preferences over inflation and unemployment: Evidence from surveys of happiness. American Economic Review 2001; 91; 335-341.

Di Tella R, MacCulloch RJ, Oswald AJ. The macroeconomics of happiness. Review of Economics and Statistics 2003; 85; 809-827.

Dolan P, Kahneman D. Interpretations of utility and their implications for the valuation of health. 2006. Working paper. Tanaka Business School. Imperial College, London.

Easterlin RA. Does economic growth improve the human lot? Some empirical evidence. In: David PA, Reder MW (Eds.), Nations and households in economic growth: Essays in honor of Moses Abramowitz. Academic Press: New York; 1974. p. 89-125.

Easterlin RA. Explaining happiness. Proceedings of the National Academy of Sciences 2003; 100; 11176-11183.

Fahey T, Smyth E. Do subjective indicators measure welfare? Evidence from 33 European societies. European Societies 2004; 6; 5-27. 
Frey BS, Stutzer A. Happiness and economics. Princeton University Press: Princeton; 2002.

Gilbert D. Stumbling on happiness. Alfred A Knopf: New York; 2006.

Giles WH, Croft JB, Keenan NL, Lane MJ, Wheeler FC. The validity of self-reported hypertension and correlates of hypertension awareness among blacks and whites with the stroke belt. American Journal of Preventive Medicine 1995; 11; 163-169.

Goldberg DP, Gater T, Sartorious N, Ustun TB, Piccinelli M, Gureje O, Rutter C. The validity of two versions of the GHQ in the WHO study of mental illness in general health care. Psychological Medicine 1997; 27; 191-197.

Graham C. Insights on development from the economics of happiness. World Bank Research Observer 2005; 20; 201-231.

Gravelle H, Sutton M. Income, relative income, and self-reported health in Britain 1979-2000. March 2006. Working paper, University of York.

Helliwell J. How's life? Combining individual and national variables to explain subjective well-being. Economic Modelling 2003; 20; 331-360.

$\mathrm{Hu} \mathrm{Y}$, Stewart-Brown S, Twigg L, Weich S. Can the 12-item General Health Questionnaire be used to measure positive mental heath? Unpublished paper; University of Warwick; 2006.

Hudson J. Institutional trust and subjective well-being across the EU. Kyklos 2006; 59; 43-62.

Huppert FA, Whittington JE. Evidence for the independence of positive and negative well-being: Implications for quality of life assessment. British Journal of Health Psychology 2003; 8; 107-122.

Inglehart R. The diminishing utility of economic growth: From maximizing security toward maximizing subjective well-being. Critical Review 1996; 10; 509-531.

Johannesson M, Jonsson B, Borgquist L. Willingness to pay for antihypertensive therapy - Results of a Swedish pilot study. Journal of Health Economics 1991; $10 ; 461-474$.

Jonas BS, Lando JF. Negative affect as a prospective risk factor for hypertension. Psychosomatic Medicine 2000; 62; 188-196.

Joynt KE, Whellan DJ, O'Connor CM. Depression and cardiovascular disease: Mechanisms of interaction. Biological Psychiatry 2003; 54; 248-261.

Kahneman D, Krueger AB, Schkade D, Schwarz N, Stone A. Toward national wellbeing accounts. American Economic Review 2004; 94; 429-434.

Kahneman D, Riis J. Living and thinking about it: Two perspectives on life. To appear in The science of well-being: Integrating neurobiology, psychology, and social science. Eds: F. Huppert, N. Baylis and B. Kaverne. Oxford University Press. 2005.

Kearney PM, Whelton M, Reynolds K, Muntner P, Whelton PK, He J. Global burden of hypertension: analysis of worldwide data. Lancet $2005 ; 365 ; 217-223$.

Kenny C. Does growth cause happiness, or does happiness cause growth? Kyklos $1999 ; 52 ; 3-25$.

Lawes CMM, Vander Hoom S, Law MR, Elliott P, MacMahon S, Rodgers A. Blood pressure and the global burden of disease 2000. Part 1: Estimates of blood pressure levels. Journal of Hypertension 2006; 24; 413-422.

Lazaro ML, Valdes M, Marcos T, Guarch J. Borderline hypertension, daily stress and psychological variables. Stress Medicine 1993; 9; 215-220.

Lester D. National ratings of happiness, suicide, and homicide. Psychological Reports 2002; 91; 758-758. 
Liman-Costa MF, Peixoto SV, Firmo JOA. Validity of self-reported hypertension and its determinants (the Bambui study). Revista de Saude Publica 2004; 38; 637642.

Marmot MG. The status syndrome: How social standing affects our health and longevity. Owl Books: New York; 2004.

Martin LM, Leff M, Calonge N, Garrett C, Nelson DE. Validation of self-reported chronic conditions and health services in a managed care population. American Journal of Preventive Medicine 2000; 18; 215-218.

McClave JT, Benson PG and Sincich T. Statistics for Business and Economics. Prentice Hall. New York: 2001.

Muhajarine N, Mustard C, Roos LL, Young TK, Gelskey DE. Comparison of survey and physician claims data for detecting hypertension. Journal of Clinical Epidemiology 1997; 50; 711-718.

$\mathrm{Ng}$ YK. A case for happiness, cardinalism, and interpersonal comparability. Economic Journal 1997; 107; 1848-1858.

Offer A. The challenge of affluence: Self-control and well-being in the United States and Britain since 1950. Oxford University Press: Oxford; 2006.

Ostir GV, Markides KS, Peek MK, Goodwin JS. The association between emotional well-being and the incidence of stroke in older adults. Psychosomatic Medicine $2001 ; 63 ; 210-215$.

Ostroot NM, Snyder WW. Measuring cultural bias in a cross-cultural study. Social Indicators Research 1985; 17; 243-251.

Oswald AJ. Happiness and economic performance. Economic Journal 1997; 107; 1815-1831.

Owen CG, Whincup PH, Cook DG. Are early life factors responsible for international differences in adult blood pressure? An ecological study. International Journal of Epidemiology 2005; 34; 649-654.

Roy JP. Socioeconomic status and health: a neurobiological perspective. Medical Hypotheses 2004; 62; 222-227.

Rutledge T, Hogan BE. A quantitative review of prospective evidence linking psychological factors with hypertension development. Psychosomatic Medicine 2002; 64; 758-766.

Schyns P. Wealth of nations, individual income and life satisfaction in 42 countries: A multilevel approach. Social Indicators Research 2002; 60; 5-40.

Smith DM, Langa M, Kabeto MU, Ubel PA. Health, wealth and happiness: Financial resources buffer subjective well-being after the onset of a disability. Psychological Science 2005; 16; 663-666.

Stamler R, Shipley M, Elliott P, Dyer A, Sans S, Stamler J. Higher blood pressure in adults with less education - Some explanations from INTERSALT. Hypertension 1992; 19; 237-241.

Steel P, Ones DS. Personality and happiness: A national-level analysis. Journal of Personality and Social Psychology 2002; 83; 767-781.

Steptoe A. Psychosocial factors in the development of hypertension. Annals of Medicine 2000; 32; 371-375.

Steptoe A, Wardle J. Positive affect and biological function in everyday life. Neurobiology of Aging 2005; 26 (Supplement 1); S108-S1 12.

Steptoe A, Wardle J, Marmot M. Positive affect and health-related neuroendocrine, cardiovascular, and inflammatory processes. Proceedings of the National Academy of Science of the United States 2005; 102; 6508-6512. 
Strasser T. Hypertension: The East European experience. American Journal of Hypertension 1998; 11; 756-758.

Theodossiou I. The effects of low-pay and unemployment on psychological wellbeing: A logistic regression approach. Journal of Health Economics 1998; 17; 85-104.

Van Praag B, Ferrer-I-Carbonell A. Happiness quantified: A satisfaction calculus approach. Oxford University Press: Oxford; 2004.

Vargas CM, Burt VL, Gillum RF, Pamuk ER. Validity of self-reported hypertension in the National Health and Nutrition Examination Survey III, 1988-91. Preventive Medicine 1997; 26; 678-685.

Veenhoven R. Quality-of-life in individualistic society. Social Indicators Research 1999; 48; 157-186.

Vemuri AW, Constanza R. The role of human, social, built, and natural capital in explaining life satisfaction at the country level: Toward a National Well-being Index (NWI). Ecological Economics 2006; 58; 119-133.

Wolf-Maier K, Cooper RS, Banergas JR, Giampaoli S, Hense HW, Joffres M, Kastarinen M, Pouler N, Primatesta P, Rodriguez-Artalejo F, Stegmayr B, Thamm M, Tuomilehto J, Vanuzzo D, Vescio F. Hypertension, prevalence and blood pressure levels in 6 European countries, Canada, and the United States. Journal of the American Medical Association 2003; 289; 2363-2369.

Yoon S, Zhang ZJ. Validity of self-reported hypertension, hypercholesterolemia, and overweight among US adults: The National Health and Nutrition Examination 199-2002. Stroke 2006; 37; 716-716. 
Figure 1.

The Inverse Correlation Between Blood Pressure Problems and Happiness: 16 European Nations

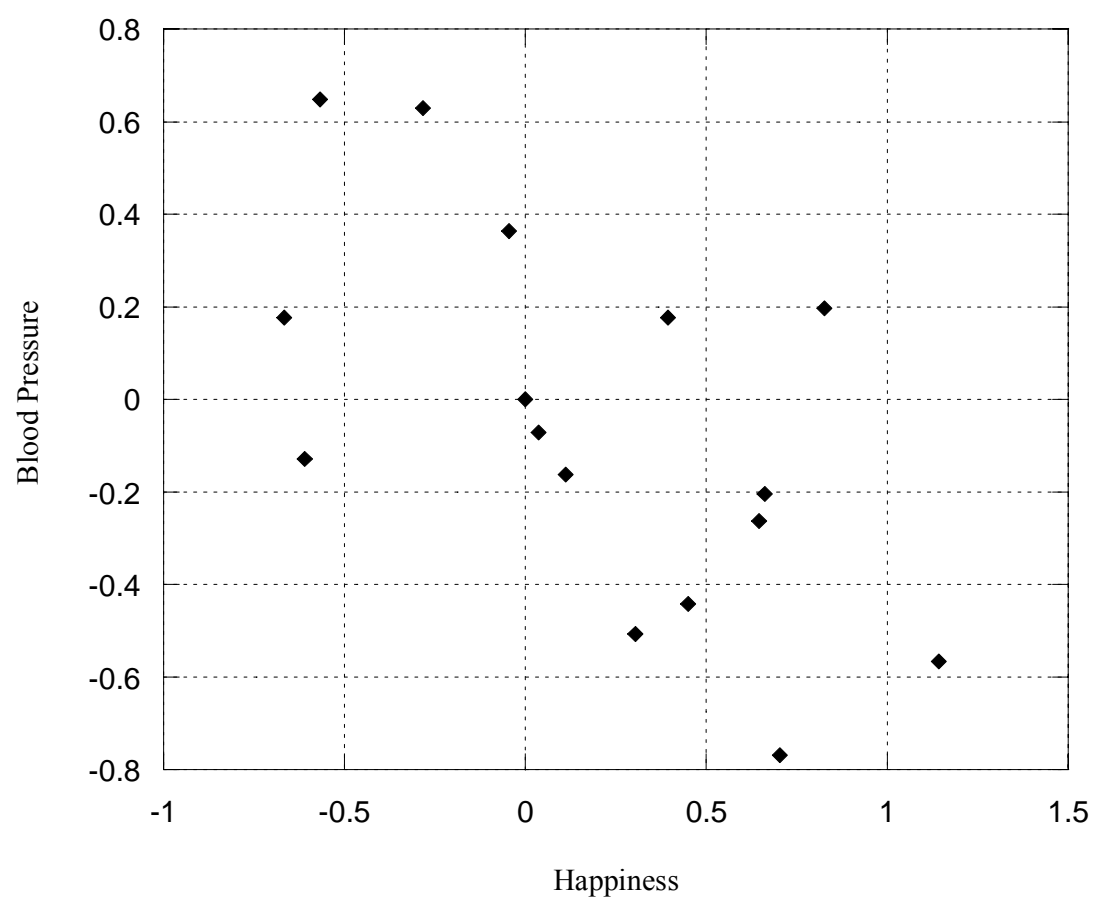


Figure 2.

The Inverse Correlation Between Hypertension and Life Satisfaction: 16 European Nations Aggregated into Quartiles

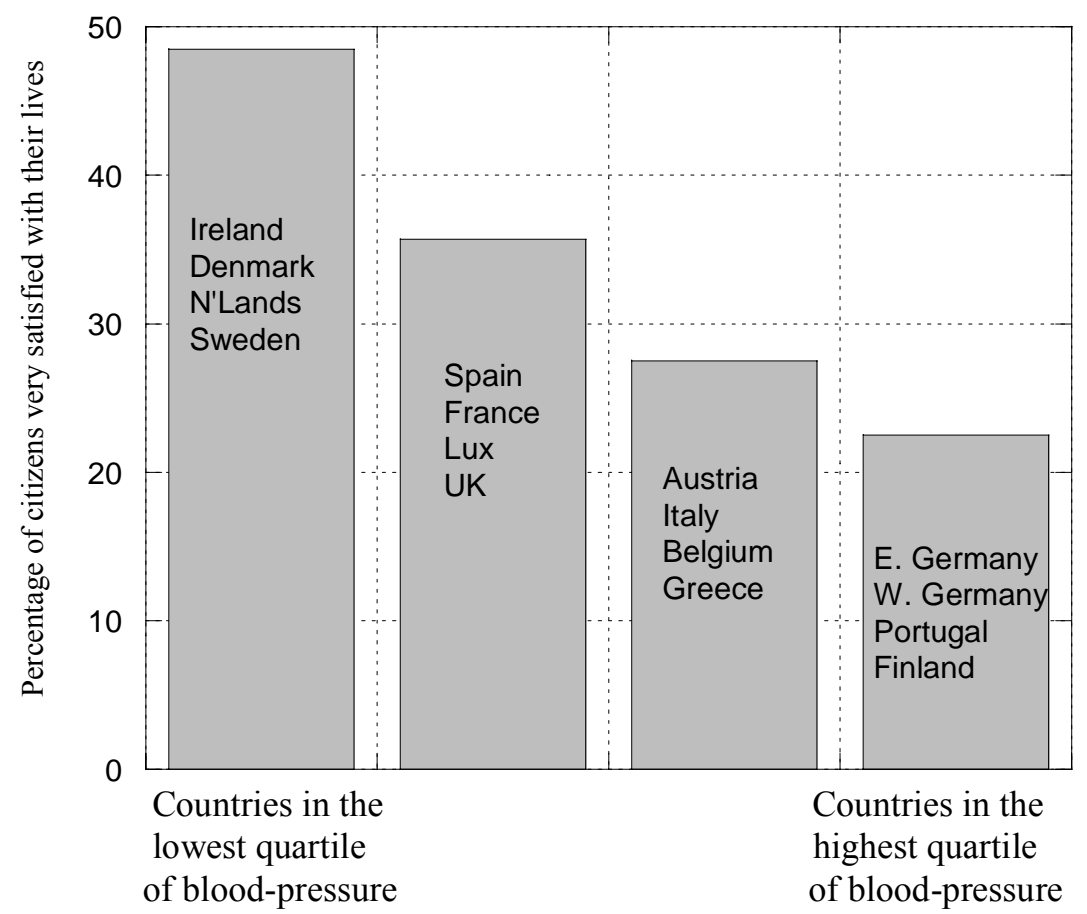


Table 1. Descriptive Data on High Blood-Pressure and Life Satisfaction Levels

a) Blood pressure. Would you say that you have had problems of high blood pressure? (\%)

$\begin{array}{lccccr} & \text { Not at all } & \begin{array}{c}\text { No more } \\ \text { than usual }\end{array} & \begin{array}{c}\text { Rather more } \\ \text { than usual }\end{array} & \begin{array}{c}\text { Much more } \\ \text { than usual }\end{array} & \text { N } \\ \text { Belgium } & 67 & 25 & 6 & 2 & 1,015 \\ \text { Denmark } & 79 & 11 & 7 & 3 & 977 \\ \text { West Germany } & 58 & 30 & 10 & 2 & 944 \\ \text { Greece } & 70 & 20 & 7 & 4 & 990 \\ \text { Italy } & 67 & 18 & 10 & 5 & 964 \\ \text { Spain } & 71 & 21 & 6 & 2 & 989 \\ \text { France } & 74 & 17 & 8 & 2 & 989 \\ \text { Ireland } & 75 & 20 & 4 & 1 & 977 \\ \text { Luxembourg } & 74 & 16 & 8 & 2 & 581 \\ \text { Netherlands } & 77 & 18 & 4 & 0 & 980 \\ \text { Portugal } & 50 & 33 & 12 & 4 & 977 \\ \text { UK } & 78 & 15 & 5 & 2 & 1,273 \\ \text { East Germany } & 50 & 35 & 12 & 3 & 961 \\ \text { Finland } & 64 & 24 & 10 & 3 & 973 \\ \text { Sweden } & 80 & 13 & 5 & 1 & 965 \\ \text { Austria } & 65 & 24 & 10 & 1 & 962 \\ \text { EU } & 69 & 21 & 8 & 2 & 15,517\end{array}$

b) Life satisfaction. Would you say that you are very satisfied, fairly satisfied, not very satisfied, or not at all satisfied with the life you lead? (\%)

$\begin{array}{lccccr} & \begin{array}{c}\text { Not at all } \\ \text { satisfied }\end{array} & \begin{array}{c}\text { Not very } \\ \text { satisfied }\end{array} & \begin{array}{c}\text { Fairly } \\ \text { satisfied }\end{array} & \begin{array}{c}\text { Very } \\ \text { satisfied }\end{array} & \mathrm{N} \\ \text { Belgium } & 2 & 12 & 55 & 31 & 1,027 \\ \text { Denmark } & 0 & 3 & 31 & 66 & 1,000 \\ \text { West Germany } & 2 & 10 & 61 & 27 & 996 \\ \text { Greece } & 7 & 18 & 51 & 24 & 1,004 \\ \text { Italy } & 2 & 15 & 71 & 11 & 988 \\ \text { Spain } & 1 & 11 & 57 & 31 & 997 \\ \text { France } & 2 & 13 & 61 & 24 & 991 \\ \text { Ireland } & 1 & 7 & 55 & 38 & 991 \\ \text { Luxembourg } & 1 & 4 & 44 & 51 & 598 \\ \text { Netherlands } & 1 & 5 & 42 & 52 & 1,005 \\ \text { Portugal } & 3 & 21 & 59 & 18 & 999 \\ \text { UK } & 2 & 8 & 52 & 37 & 1,301 \\ \text { East Germany } & 3 & 18 & 61 & 18 & 999 \\ \text { Finland } & 2 & 9 & 63 & 27 & 992 \\ \text { Sweden } & 1 & 6 & 55 & 38 & 999 \\ \text { Austria } & 1 & 6 & 49 & 44 & 998 \\ \text { EU } & 2 & 10 & 54 & 33 & 15,885\end{array}$


c) Cross-tabulation of blood pressure and life satisfaction (at the individual level: $N=15,474$ )

$\begin{array}{lcccrr} & \begin{array}{l}\text { Not at all } \\ \text { satisfied }\end{array} & \begin{array}{l}\text { Not very } \\ \text { satisfied }\end{array} & \begin{array}{l}\text { Fairly } \\ \text { satisfied }\end{array} & \begin{array}{c}\text { Very } \\ \text { satisfied }\end{array} & \text { All } \\ \text { Blood pressure problems } & & & & & \\ \text { Not at all } & 0.9 & 5.3 & 36.2 & 26.5 & 68.9 \\ \text { No more than usual } & 0.5 & 2.7 & 12.9 & 5.1 & 21.2 \\ \text { Rather more than usual } & 0.3 & 1.6 & 4.2 & 1.5 & 7.6 \\ \text { Much more than usual } & 0.3 & 0.6 & 1.0 & 0.4 & 2.3 \\ \text { All } & 1.9 & 10.3 & 54.3 & 33.5 & 100.0\end{array}$

Cells here are overall percentages.

Source Eurobarometer \#56.1: Social Exclusion and Modernization of Pension Systems, September-October 2001. ICPSR \#3475 
Table 2. Blood-Pressure Equations: Full Sample (Eurobarometer Data 2001)

\begin{tabular}{|c|c|c|c|c|}
\hline & (1) & (2) & (3) & (4) \\
\hline & OLS & OLS & OLS & OLOGIT \\
\hline Austria & $.0628(2.03)$ & $.0601(1.94)$ & $.0493(1.58)$ & $.1772(1.80)$ \\
\hline Denmark & $-.1008(3.26)$ & $-.0910(2.94)$ & $-.0857(2.73)$ & $-.5664(5.18)$ \\
\hline East Germany & $.2197(7.08)$ & $.2203(7.10)$ & $.2079(6.66)$ & $.6290(6.70)$ \\
\hline Finland & $.0931(3.01)$ & .0949 (3.07) & $.0859(2.75)$ & 1967 (1.99) \\
\hline France & $-.0113(0.37)$ & $-.0103(0.34)$ & $-.0160(0.52)$ & $-.1628(1.60)$ \\
\hline Greece & $.0102(0.33)$ & $.0048(0.16)$ & $.0018(0.06)$ & $-.1284(1.26)$ \\
\hline Ireland & $-.0565(1.83)$ & $-.0605(1.96)$ & $-.0610(1.95)$ & $-.2044(1.96)$ \\
\hline Italy & $.1050(3.39)$ & $.1006(3.24)$ & $.1042(3.34)$ & $.1764(1.76)$ \\
\hline Luxembourg & $-.0280(0.78)$ & $-.0326(0.88)$ & $-.0331(0.89)$ & $-.2635(2.14)$ \\
\hline Netherlands & $-.1313(4.26)$ & $-.1298(4.20)$ & $-.1227(3.94)$ & $-.4413(4.19)$ \\
\hline Portugal & $.2695(8.73)$ & $.2536(8.13)$ & $.2429(7.63)$ & $.6478(6.60)$ \\
\hline Spain & $.0002(0.01)$ & $-.0074(0.24)$ & $-.0081(0.26)$ & $-.0715(0.70)$ \\
\hline Sweden & $-.1825(5.89)$ & $-.1792(5.77)$ & $-.1715(5.45)$ & $-.7688(6.98)$ \\
\hline UK & $-.0922(3.18)$ & $-.0940(3.24)$ & $-.1092(3.74)$ & $-.5073(5.13)$ \\
\hline West Germany & $.1158(3.72)$ & $.1145(3.67)$ & $.1043(3.33)$ & $.3636(3.77)$ \\
\hline Age & $.0108(6.81)$ & $.0140(7.78)$ & $.0128(5.88)$ & $.0675(9.18)$ \\
\hline $\mathrm{Age}^{2}$ & $.0000(0.39)$ & $-.0000(1.31)$ & $-.0000(1.63)$ & $-.0003(4.89)$ \\
\hline Male & $-.0108(0.98)$ & $-.0099(0.89)$ & $.0023(0.19)$ & $.0222(0.55)$ \\
\hline Age left schooling & & $-.0035(3.70)$ & $-.0069(4.60)$ & $-.0173(3.53)$ \\
\hline Constant & $.9156(22.31)$ & $.9008(21.71)$ & $1.0923(13.51)$ & \\
\hline _cut 1 & & & & 2.6653 \\
\hline _cut 2 & & & & 4.2449 \\
\hline _cut 3 & & & & 5.8586 \\
\hline Personal controls & No & No & Yes & Yes \\
\hline Adjusted $\mathrm{R}^{2}$ & .1117 & .1122 & .1178 & \\
\hline Pseudo $\mathrm{R}^{2}$ & & & & .0847 \\
\hline $\mathrm{N}$ & 15,517 & 15,457 & 15,396 & 15,396 \\
\hline
\end{tabular}

Notes Each of the four regression equations is to be read vertically. The dependent variable here is a measure of reported problems of high blood-pressure. 'Personal controls' are 10 dummy variables relating to the individual's experiences before the age of 18; 16 labour-force status dummies; and 8 marital-status dummies. Belgium is the excluded nation. The question that forms the dependent variable is here, and in some later tables, "Would you say that you have not at all, no more than usual, rather more than usual, much more than usual...had problems of high blood pressure?" where $1=$ not at all; $2=$ no more than usual; $3=$ rather more than usual; $4=$ much more than usual. t-statistics are in parentheses.

Source Eurobarometer \#56.1: Social Exclusion and Modernization of Pension Systems, September-October 2001. ICPSR \#3475 
Table 3. Blood-Pressure Equations: Males (Eurobarometer Data 2001)

\begin{tabular}{|c|c|c|c|c|}
\hline & (1) & (2) & (3) & (4) \\
\hline & OLS & OLS & OLS & OLOGIT \\
\hline Austria & $.1409(3.16)$ & $.1403(3.14)$ & $.1199(2.67)$ & $.3827(2.67)$ \\
\hline Denmark & $-.0274(0.63)$ & $-.0245(0.56)$ & $-.0584(1.31)$ & $-.3844(2.51)$ \\
\hline East Germany & $.1817(4.06)$ & $.1816(4.06)$ & $.1734(3.86)$ & $.5432(3.92)$ \\
\hline Finland & $.1643(3.63)$ & $.1639(3.62)$ & $.1295(2.82)$ & $.3771(2.60)$ \\
\hline France & $-.0028(0.06)$ & $-.0023(0.05)$ & $-.0217(0.50)$ & $-.1751(1.18)$ \\
\hline Greece & $.0009(0.02)$ & $-.0006(0.02)$ & $-.0147(0.33)$ & $-.1596(1.08)$ \\
\hline Ireland & $-.0519(1.18)$ & $-.0533(1.21)$ & $-.0549(1.23)$ & $-.1840(1.21)$ \\
\hline Italy & $.0992(2.25)$ & $.0982(2.22)$ & $.0988(2.22)$ & $.1809(1.25)$ \\
\hline Luxembourg & $-.0083(0.16)$ & $-.0189(0.36)$ & $-.0404(0.77)$ & $-.2532(1.44)$ \\
\hline Netherlands & $-.1356(3.10)$ & $-.1349(3.09)$ & $-.1308(2.96)$ & $-.4840(3.16)$ \\
\hline Portugal & $.1992(4.43)$ & $.1950(4.31)$ & $.1725(3.72)$ & .5379 (3.69) \\
\hline Spain & $-.0190(0.44)$ & $-.0208(0.48)$ & $-.0152(0.35)$ & $-.1204(0.81)$ \\
\hline Sweden & $-.1680(3.81)$ & $-.1699(3.84)$ & $-.1781(3.99)$ & $-.7350(4.69)$ \\
\hline UK & $-.0387(0.93)$ & $-.0396(0.95)$ & $-.0544(1.30)$ & $-.3437(2.41)$ \\
\hline West Germany & $.1427(3.23)$ & $.1418(3.21)$ & $.1380(3.11)$ & $.4232(3.03)$ \\
\hline Age & $.0116(5.11)$ & $.0128(4.96)$ & $.0123(3.90)$ & $.0679(6.24)$ \\
\hline $\mathrm{Age}^{2}$ & $.0000(0.28)$ & $-.0000(0.67)$ & $-.0000(0.97)$ & $-.0003(3.30)$ \\
\hline Age left schooling & & $-.0010(0.79)$ & $.0008(0.40)$ & $.0011(0.17)$ \\
\hline Constant & $.8842(15.21)$ & $.8746(14.89)$ & $.9187(8.17)$ & \\
\hline cut 1 & & & & 3.0999 \\
\hline cut 2 & & & & 4.7086 \\
\hline _cut 3 & & & & 6.3148 \\
\hline Personal controls & No & No & Yes & Yes \\
\hline Adjusted $\mathrm{R}^{2}$ & .1012 & .1013 & .1145 & \\
\hline Pseudo $\mathrm{R}^{2}$ & & & & .0805 \\
\hline $\mathrm{N}$ & 7,400 & 7,374 & 7,345 & 7,345 \\
\hline
\end{tabular}

Notes The dependent variable here is a measure of reported blood-pressure problems. 'Personal controls' are 10 dummy variables relating to the individual's experiences before the age of 18; 16 labour-force status dummies; and 8 marital-status dummies. t-statistics are in parentheses. Belgium is the excluded nation.

Source Eurobarometer \#56.1: Social Exclusion and Modernization of Pension Systems, September-October 2001. ICPSR \#3475 
Table 4. Blood-Pressure Equations: Females (Eurobarometer Data 2001)

\begin{tabular}{|c|c|c|c|c|}
\hline & (1) & (2) & (3) & (4) \\
\hline & OLS & OLS & OLS & OLOGIT \\
\hline Austria & $-.0044(0.10)$ & $-.0090(0.21)$ & $-.0313(0.72)$ & $-.0333(0.24)$ \\
\hline Denmark & $-.1724(3.95)$ & $-.1573(3.59)$ & $-.1608(3.58)$ & $-.7694(4.87)$ \\
\hline East Germany & $.2509(5.84)$ & $.2522(5.87)$ & $.2325(5.37)$ & $.6592(5.13)$ \\
\hline Finland & $.0377(0.89)$ & $.0439(1.04)$ & $.0127(0.30)$ & $.0343(0.25)$ \\
\hline France & $-.0187(0.43)$ & $-.0174(0.40)$ & $-.0311(0.72)$ & $-.1534(1.09)$ \\
\hline Greece & $.0221(0.51)$ & $.0136(0.31)$ & $-.0125(0.28)$ & $-.1249(0.88)$ \\
\hline Ireland & $-.0606(1.40)$ & $-.0650(1.50)$ & $-.0588(1.34)$ & $-.2291(1.59)$ \\
\hline Italy & $.1109(2.56)$ & $.1028(2.37)$ & $.0997(2.28)$ & $.1736(1.25)$ \\
\hline Luxembourg & $-.0455(0.90)$ & $-.0449(0.85)$ & $-.0691(1.31)$ & $-.2815(1.62)$ \\
\hline Netherlands & $-.1248(2.87)$ & $-.1236(2.84)$ & $-.1162(2.65)$ & $-.4048(2.76)$ \\
\hline Portugal & $.3252(7.65)$ & $.2982(6.93)$ & $.2551(5.74)$ & $.6997(5.18)$ \\
\hline Spain & $.0190(0.44)$ & $.0049(0.11)$ & $-.0004(0.01)$ & $-.0391(0.28)$ \\
\hline Sweden & $-.1943(4.48)$ & $-.1846(4.24)$ & $-.1820(4.09)$ & $-.8044(5.16)$ \\
\hline UK & $-.1388(3.43)$ & $-.1399(3.46)$ & $-.1589(3.90)$ & $-.6692(4.84)$ \\
\hline West Germany & $.0903(2.06)$ & $.0905(2.06)$ & $.0744(1.69)$ & $.2841(2.13)$ \\
\hline Age & $.0099(4.48)$ & $.0146(5.84)$ & $.0119(3.91)$ & $.0650(6.42)$ \\
\hline $\mathrm{Age}^{2}$ & $.0000(0.83)$ & $-.0000(1.04)$ & $-.0000(0.93)$ & $-.0003(3.38)$ \\
\hline Age left schooling & & $-.0054(4.11)$ & $-.0110(5.09)$ & $-.0352(4.82)$ \\
\hline Constant & $.9376(16.48)$ & $.9205(16.01)$ & $1.3202(11.04)$ & \\
\hline cut 1 & & & & 2.0772 \\
\hline cut 2 & & & & 3.6467 \\
\hline _cut 3 & & & & 5.2764 \\
\hline Personal controls & No & No & Yes & Yes \\
\hline Adjusted $\mathrm{R}^{2}$ & .1236 & .1247 & .1375 & \\
\hline Pseudo $\mathrm{R}^{2}$ & & & & .0938 \\
\hline $\mathrm{N}$ & 8,117 & 8,083 & 8,051 & 8,051 \\
\hline
\end{tabular}

Notes The dependent variable here is a measure of reported blood-pressure problems. 'Personal controls' are 10 dummy variables relating to the individual's experiences before the age of $18 ; 16$ labour-force status dummies; and 8 marital-status dummies. t-statistics are in parentheses. Belgium is the excluded nation.

Source Eurobarometer \#56.1: Social Exclusion and Modernization of Pension Systems, September-October 2001. ICPSR \#3475 
Table 5. Life-Satisfaction and Happiness Equations (For 3 Data Sets)

(1)

\begin{tabular}{|c|c|c|c|c|}
\hline & (1) & (2) & (3) & (4) \\
\hline & Life Sat. & Life Sat. & Life Sat. & Happiness \\
\hline Austria & .7166 (7.97) & $.3113(11.30)$ & $.1874(4.47)$ & $-.0736(1.77)$ \\
\hline Denmark & $1.7312(17.84)$ & $1.7569(64.61)$ & $1.0838(24.11)$ & $.6664(14.96)$ \\
\hline West Germany & $-.0729(0.82)$ & $-.1499(5.76)$ & $-.4009(9.58)$ & $-.5175(12.44)$ \\
\hline Greece & $-.6553(7.00)$ & $-1.2310(46.52)$ & $-.9375(22.92)$ & $-1.0484(25.37)$ \\
\hline Italy & $-.8091(9.00)$ & $-.5279(20.16)$ & $-.5312(8.69)$ & $-1.2620(20.66)$ \\
\hline Spain & $.0269(0.30)$ & $-.2093(7.92)$ & $-.4084(9.13)$ & $-.4272(9.49)$ \\
\hline France & $-.2508(2.79)$ & $-.4712(18.03)$ & $-.8708(15.18)$ & $-.3826(6.76)$ \\
\hline Ireland & $.4128(4.60)$ & $.6594(25.15)$ & $.0089(0.17)$ & .1547 (2.99) \\
\hline Luxembourg & $.8609(7.96)$ & $.7322(24.40)$ & $.4709(10.06)$ & $.1941(4.16)$ \\
\hline Netherlands & $.9406(10.40)$ & $.9576(36.99)$ & .0925 (1.97) & $-.0426(0.91)$ \\
\hline Portugal & $-.5965(6.41)$ & $-1.0906(41.23)$ & $-1.3899(31.14)$ & $-1.0065(22.50)$ \\
\hline UK & $.3938(4.66)$ & $.5035(20.35)$ & $-.3248(7.76)$ & $-.1724(4.09)$ \\
\hline East Germany & $-.5577(6.22)$ & $-.7309(28.26)$ & $-.9418(16.84)$ & $-.7599(13.67)$ \\
\hline Finland & $.0783(0.87)$ & $.2262(8.31)$ & $.5157(12.65)$ & $.3572(8.77)$ \\
\hline Sweden & $.4342(4.81)$ & $.8286(30.35)$ & $.4296(10.35)$ & $.2320(5.59)$ \\
\hline Age & $-.0606(9.49)$ & $-.0556(29.96)$ & $-.0592(20.24)$ & $-.0660(22.41)$ \\
\hline $\mathrm{Age}^{2}$ & $.0006(9.61)$ & $.0005(29.88)$ & $.0006(21.10)$ & $.0006(21.54)$ \\
\hline Male & $-.1347(3.80)$ & $-.0801(7.95)$ & $-.1126(6.71)$ & $-.1210(7.19)$ \\
\hline Age left schooling & $.0279(6.22)$ & $\mathrm{n} / \mathrm{a}$ & $.0402(18.04)$ & $.0328(14.67)$ \\
\hline cut 1 & -5.3108 & -4.4028 & -5.8812 & -7.3341 \\
\hline cut 2 & -3.1896 & -2.4880 & -5.3270 & -6.6011 \\
\hline cut 3 & -.0899 & .6171 & -4.7165 & -5.8587 \\
\hline cut 4 & & & -4.0504 & -5.1357 \\
\hline cut 5 & & & -3.5589 & -4.6052 \\
\hline cut 6 & & & -2.7168 & -3.6172 \\
\hline cut 7 & & & -2.2229 & -3.0341 \\
\hline cut 8 & & & -1.4008 & -2.1261 \\
\hline _cut 9 & & & -.1242 & -.7923 \\
\hline cut 10 & & & .9901 & .4328 \\
\hline$\overline{\text { Schooling dummies }}$ & 0 & 9 & 0 & 0 \\
\hline Labour force dummies & 16 & 6 & 2 & 2 \\
\hline Marital status dummies & 9 & 9 & 4 & 4 \\
\hline Year dummies & 0 & 6 & 1 & 1 \\
\hline Pseudo $\mathrm{R}^{2}$ & .0998 & .0949 & .0393 & .0331 \\
\hline $\mathrm{N}$ & 15,760 & 185,711 & 47,235 & 47,244 \\
\hline
\end{tabular}

Notes The dependent variable here is a measure of well-being (life satisfaction in the first three columns; happiness in the fourth column). These are ordered logit equations. Belgium is the excluded country. $t$-statistics are in parentheses.

Sources Column 1) Eurobarometer \#56.1: Social Exclusion and Modernization of Pension Systems, SeptemberOctober 2001. ICPSR \#3475. Column 2) Eurobarometer Trends file ICPSR \#4357 for years 1994, 1995, 1997-2002. Columns 3 and 4) European Social Surveys 2002 and 2004. 
Table 6. GHQ-N6 Psychological Distress Equations (Eurobarometer Data 2001)

(1)

Austria

Denmark

East Germany

Finland

France

Greece

Ireland

Italy

Luxembourg

Netherlands

Portugal

Spain

Sweden

UK

West Germany

Age

$\mathrm{Age}^{2}$

Male

Age left schooling

Constant

Personal controls

Adjusted $\mathrm{R}^{2}$

$\mathrm{N}$

No

.0296

15,441
$.0545(0.33)$

$-.3185(1.96)$

.9965 (6.06)

$1.0331(6.34)$

$.7918(4.85)$

$.7441(4.58)$

$-.1711(1.05)$

2.1916 (13.32)

$-.0001(0.01)$

$-.3660(2.23)$

$.7703(4.68)$

$.0049(0.03)$

$.0170(0.10)$

$.1194(0.78)$

$.0574(0.35)$
(2)

$.0234(0.14)$

$-.3284(2.04)$

.9405 (5.76)

$1.0107(6.26)$

.7713 (4.77)

$.7436(4.61)$

$-.1663(1.03)$

2.1751 (13.33)

$-.0335(0.18)$

$-.3899(2.40)$

$.7815(4.78)$

$.0285(0.18)$

$.0139(0.09)$

$.1159(0.77)$

$.0322(0.20)$

$.0950(11.40)$

$-.0009(11.56)$

-.6527 (11.25)

$3.2020(27.99)$

.0456

15,441
(3)

(4)

$.0155(0.10)$

$-.2952(1.83)$

$.9424(5.78)$

$1.0169(6.30)$

.7754 (4.79)

.7257 (4.50)

$-.1789(1.10)$

2.1603 (13.23)

$-.0408(0.21)$

$-.3846(2.37)$

$.7288(4.42)$

$.0038(0.02)$

$.0075(0.05)$

$.1106(0.73)$

$.0288(0.18)$

$.1058(11.21)$

$-.0010(11.44)$

-.6501 (11.19)

$-.0119(2.41)$

$1.5442(7.12)$
No

.0460

15,379
$1.4913(3.57)$

Yes

-.0985 (0.63)

$-.6924(4.38)$

$.8156(5.21)$

.5969 (3.81)

$.6379(4.12)$

$.6818(4.33)$

$-.0254(0.16)$

$2.2381(14.26)$

$-.1069(0.57)$

-.2764 (1.77)

.4654 (2.87)

$.0852(0.55)$

$-.1259(0.81)$

$-.0158(0.11)$

$.0516(0.33)$

$.0958(8.73)$

$-.0010(9.22)$

$-.4727(7.73)$

$-.0211(2.77)$

.1349

15,379

Notes: The dependent variable is a psychological distress score measured on a scale from 0 to 18 . A GHQ-N6 score amalgamates answers to six questions: Have you recently: Lost much sleep over worry? Felt constantly under strain? Felt you could not overcome your difficulties? Been feeling unhappy and depressed? Been losing confidence in yourself? Been thinking of yourself as a worthless person? Its mean in the sample is 3.6 (s.d. 3.7).

'Personal controls' are 10 dummies relating to the individual's experiences before the age of 18; 16 labour force status dummies; and 8 marital-status dummies. Belgium is the excluded country. t-statistics are in parentheses.

Source: Eurobarometer \#56.1: Social Exclusion and Modernization of Pension Systems, September-October 2001. ICPSR \#3475 
Table 7. Ordered Logit Life-Satisfaction Equations including a High Blood-Pressure Dummy Variable (Eurobarometer Data 2001)

(1)

Blood-pressure dummy $-.8106(23.28)$
Austria
Denmark
East Germany
Finland
France
Greece
Ireland
Italy
Luxembourg
Netherlands
Portugal
Spain
Sweden
UK
West Germany
Age
Age
Male
Age left schooling

(2) $-.6985(19.55)$
$.2607(3.11)$

$1.4783(15.94)$ $-.0040(0.05)$ $.3446(3.88)$

$-.3316(3.71)$

$-.6512(7.14)$ $.3857(4.36)$

$-.7482(8.44)$ $.8828(8.54)$ $.9060(10.13)$ $-.6119(6.83)$ $-.0101(0.11)$ $.6603(7.40)$ $-.5311(5.88)$ $.0062(0.07)$
(3) $-.7417(19.76)$ $.2690(3.21)$ $1.4587(15.66)$ $-.0086(0.10)$ $.3212(3.60)$ $-.3187(3.56)$ $-.6339(6.93)$ $.4139(4.67)$ $-.7317(8.24)$ .8541 (7.98) $.9217(10.28)$ $-.5775(6.38)$ $.0170(0.19)$ $.6890(7.70)$ $-.5232(5.79)$ $.0190(0.21)$ $-.0366(7.00)$ $.0004(7.94)$ $.0107(0.33)$ .0087 (3.20)

$$
\begin{array}{r}
-4.2613 \\
-2.2794 \\
.4616
\end{array}
$$

No

$$
\begin{aligned}
& -4.2785 \\
& -2.2654
\end{aligned}
$$

.65622

No

$$
\begin{array}{r}
-4.8021 \\
-2.7869 \\
.1458
\end{array}
$$$$
.0515
$$$$
15,474
$$

15,474
(4) $-.4846(20.00)$ $.3814(4.45)$ $1.7296(17.50)$ $.1502(1.64)$ $.3686(4.01)$ $-.2480(2.74)$ $-.6584(6.96)$ $.4028(4.43)$ $-.7675(8.41)$ $.8853(8.03)$ $.9080(9.89)$ $-.4689(4.97)$ $.0190(0.21)$ $.7521(8.23)$ $-.4637(5.07)$ $-.0088(0.10)$ $-.0576(8.85)$ $.0006(9.58)$ $-.1233(3.43)$ $.0263(5.76)$

Yes

$$
\begin{array}{r}
-6.1807 \\
-4.0210 \\
-.8439
\end{array}
$$

.1120

Notes: 'Blood-pressure dummy' is a dummy variable for reporting anything except Not At All to the question: "Would you say that you have had problems of high blood pressure?". 'Personal controls' are 10 dummies relating to the individual's experiences before the age of 18; 16 labour force status dummies; and 8 marital-status dummies. Belgium is the excluded country. $t$-statistics are in parentheses.

Source: Eurobarometer \#56.1: Social Exclusion and Modernization of Pension Systems, September-October 2001. ICPSR \#3475 


\section{Table 8. Ordered Logit Life-Satisfaction Equations including a High Blood-Pressure Dummy Variable (NCDS Data)}

Blood-pressure dummy -..1920(3.65)
Male
Age left schooling
BMI
BMI $^{2}$
Underweight
Slightly overweight
Very overweight

Blood-pressure dummy -.1920 (3.65)

BMI

$\mathrm{BMI}^{2}$

Slightly overweight

Very overweight

Personal controls

Cut 1

Cut 2

Cut 3

Cut 4

Cut 5

Cut 6

Cut 7

Cut 8

Cut 9

Cut 10

Pseudo $\mathrm{R}^{2}$

$\mathrm{N}$
(1)

No

(2)

$$
\begin{array}{r}
-.1979(3.72) \\
-.1961(5.80) \\
.0316(4.35)
\end{array}
$$

-5.2535
-4.0368
-3.5591
-2.9910
-2.4197
-1.6553
-1.1236
-.2092
1.1178
2.2642

$-5.2535$

$-3.5591$

$-2.9910$

.

0.0003

0.0003

11,265

No

$-4.7926$

1.5671
(3)

$$
\begin{array}{ll}
-.2195(3.84) & -.1704(2.97) \\
-.2955(7.61) & -.3636(8.08) \\
.0357(4.57) & .0253(3.22) \\
.1376(4.84) & .1140(4.05) \\
-.0018(3.99) & -.0013(3.04) \\
-.5012(5.59) & -.3586(3.98) \\
-.1572(3.23) & -.2047(4.19) \\
-.4895(5.77) & -.5077(5.96)
\end{array}
$$

No

Yes

$-2.6219$

$-3.6866$

$-1.4090$

$-2.4491$

$-.9384$

$-1.9674$

$-.4023$

$-1.4162$

.1744

$-.8177$

.9483

.0031

1.4842

.5773

2.4042

1.5615

3.7319

2.9507

4.8721

4.1147

$\begin{array}{rr}.0042 & .0257 \\ 10,182 & 10,144\end{array}$

Notes: 'Personal controls' are 17 ethnicity dummies; 11 labour force status dummies; and 5 marital-status dummies. t-statistics are in parentheses. The excluded category is 'about the right weight'. Individuals were asked 'Would you say you were ... 'about the right weight' etc. The 'Blood-pressure' variable is a dummy variable. Respondents were asked 'Have you ever had or been told you had high blood pressure?' Life satisfaction is scored from 0-10. Respondents were told 'here is a scale from 0-10 where ' 0 ' means that you are completely dissatisfied and ' 10 ' means that you are completely satisfied. Please enter the number which corresponds to how satisfied or dissatisfied you are about the way your life has turned out so far.' t-statistics are in parentheses.

Source: British National Child Development Study \#6, 1999/2000 


\section{Data Appendix}

\section{The Wording of the Questions in the International Data}

\section{1) Eurobarometer \#56.1}

a) Blood pressure

"Would you say that you have not at all, no more than usual, rather more than usual, much more than usual...had problems of high blood pressure?"

Here $1=$ not at all; $2=$ no more than usual; $3=$ rather more than usual; $4=$ much more than usual.

[NB. It could be argued that someone with a high but unchanging level of hypertension might give the answer 2 rather than a higher number. Nevertheless, as the great majority of the population give answer number 1, such a person would still be identified, within the paper's regression equations, as having blood-pressure problems.]

\section{b) Life satisfaction}

Would you say you are very satisfied; fairly satisfied; not very satisfied or not at all satisfied...with the life you lead?"

Here $1=$ very satisfied; 2 =fairly satisfied; $3=$ not very satisfied and $4=$ not at all satisfied.

For the empirical analysis, for clarity we reverse the order and set $1=$ not at all satisfied; $2=$ not very satisfied; $3=$ fairly satisfied and $4=$ very satisfied.

\section{2) Eurotrends}

a) Life satisfaction

"On the whole are you very satisfied; fairly satisfied; not very satisfied or not at all satisfied... with the life you lead?"

Exceptions to this are in Eurobarometer \#56.1 noted above which is included in the Eurotrends file and in Eurobarometer \#52.1 (Modern Biotechnology, Quality of Life and Consumer's access to Justice, November-December, 1999, ICPSR \#2893) and that is also included in the Eurotrends file, where the question is as follows:

"On the whole are you: very satisfied; fairly satisfied; not very satisfied or not at all satisfied...with your life in general?"

Here, in all cases, $1=$ very satisfied; $2=$ fairly satisfied; $3=$ not very satisfied and $4=$ not at all satisfied. For the empirical analysis, for clarity we reverse this order and set $1=$ not at all satisfied; $2=$ not very satisfied; $3=$ fairly satisfied and $4=$ very satisfied.

\section{3) European Social Survey}

\section{a) Happiness}

"Taking all things together, how happy would you say you are? Please use this card: 'Extremely unhappy' to 'Extremely happy' on a scale of 0-10."

\section{b) Life satisfaction}

"All things considered, how satisfied are you with your life as a whole nowadays? Please answer using this card, where 0 means extremely dissatisfied and 10 means extremely satisfied" 